\title{
Effect of Cementitious Materials on the Engineering Properties of Lightweight Aggregate Mortars Containing Recycled Water
}

\author{
Jae-In Lee, Sung-Ho Bae, Ji-Hwan Kim and Se-Jin Choi *D
}

Citation: Lee, J.-I.; Bae, S.-H.; Kim,

J.-H.; Choi, S.-J. Effect of

Cementitious Materials on the

Engineering Properties of

Lightweight Aggregate Mortars

Containing Recycled Water. Materials

2022, 15, 1967. https://doi.org/

$10.3390 / \mathrm{ma} 15051967$

Academic Editor: F. Pacheco Torgal

Received: 14 February 2022

Accepted: 3 March 2022

Published: 7 March 2022

Publisher's Note: MDPI stays neutral with regard to jurisdictional claims in published maps and institutional affiliations.

Copyright: (C) 2022 by the authors. Licensee MDPI, Basel, Switzerland. This article is an open access article distributed under the terms and conditions of the Creative Commons Attribution (CC BY) license (https:// creativecommons.org/licenses/by/ $4.0 /)$.
Department of Architectural Engineering, Wonkwang University, Iksan 54538, Korea; csj2378@hanmail.net (J.-I.L.); csj2378@naver.com (S.-H.B.); csj2378@gmail.com (J.-H.K.)

* Correspondence: csj2378@wku.ac.kr

\begin{abstract}
With the trend toward taller and larger structures, the demand for high-strength and lightweight cement concrete has increased in the construction industry. Equipment for transporting ready-mixed concrete is frequently used to bring concrete to construction sites, and washing this equipment generates a large amount of recycled water, which is an industrial by-product. In this study, we recycled this water as the pre-wetting water for lightweight aggregate and as mixing water, and we substituted blast furnace slag powder (BS) and fly ash (FA) as cementitious materials $(\mathrm{Cm})$. In addition, we evaluated the fluidity, compressive strength, tensile strength, drying shrinkage, and accelerated carbonation depth of lightweight ternary cementitious mortars (TCMs) containing artificial lightweight aggregate and recycled water. The 28-day compressive strengths of the lightweight TCM specimens with BS and FA were $47.2-51.7 \mathrm{MPa}$, except for the specimen with $20 \%$ each of BS and FA (40.2 MPa), which was higher than that of the control specimen with $100 \%$ OPC (45.9 MPa). Meanwhile, the 28-day tensile strengths of the lightweight TCM specimens containing BS and FA were $\sim 2.81-3.20 \mathrm{MPa}$, which are $\sim 13.7-29.5 \%$ higher than those of the control specimen. In this study, the TCM specimen with $5 \%$ each of BS and FA performed the best in terms of the combination of compressive strength, tensile strength, and carbonation resistance.
\end{abstract}

Keywords: recycled water; blast furnace slag powder; fly ash; strength; ternary cementitious mortar; carbonation depth

\section{Introduction}

Cement concrete, which is widely used in various fields in the construction industry, must demonstrate improved performance, such as high strength and lightweight, with the increasing demand for taller and larger structures. Ready-mixed concrete, which is mainly used at construction sites, must be transported to these sites, and the equipment used to that end undergoes a washing process after the concrete is poured. This process generates a large amount of recycled water, an industrial by-product. Some of this water is recovered through recycling facilities, but some companies use recycled water that exceeds the standard value or illegally discharge this water into rivers, causing environmental pollution [1]. To solve these environmental problems, several studies have attempted to recycle the by-products of ready-mixed concrete, such as recycled water [2-9].

Xuan et al. [2] reported that applying the slurry to concrete effectively reduces its drying shrinkage after the accelerated carbonation of slurry waste generated in a readymixed concrete plant. Zervaki et al. [5] examined the characteristics of mortar mixed with dry sludge and sludge water generated in a ready-mixed concrete plant and reported that using sludge water increased its compressive strength. Sandrolini et al. [8] evaluated the characteristics of mortar and concrete mixed with ready-mixed concrete waste wash water, reporting that this water improved their durability.

Moreover, worldwide efforts to suppress global warming are required, and the cement and concrete industry emits a large amount of greenhouse gases $[10,11]$. In the 
construction industry, cement substitutes, such as blast furnace slag powder (BS) or fly ash (FA), are widely used to reduce the amount of cement used as a part of efforts to reduce greenhouse gases or to improve the durability of concrete [12,13]. In particular, several studies have recently attempted to increase the number of cement substitutes by mixing ternary cementitious material $(\mathrm{Cm})$ with two or more cement substitutes [14-21]. Upon mixing metakaolin and silica fume into the mortar, Chu et al. [16] found that although silica fume negatively affected workability, metakaolin could alleviate this negative effect. Similarly, Andrade et al. [18] investigated the properties of ternary cementitious paste with metakaolin and nanosilica and demonstrated that adding 15\% metakaolin and 3\% nanosilica increased the compressive strength by $\sim 44 \%$ compared to that of the control specimen without these two additives. Meanwhile, after evaluating the durability of ternary concrete with BS, FA, and limestone filler, Lauch et al. [21] reported that BS and FA improved the chloride penetration resistance of concrete.

Although many studies have used the by-products of the ready-mixed concrete industry and $\mathrm{Cm}$, no research has yet been published on ternary cementitious composites with artificial lightweight aggregates and recycled water. In this study, we used recycled water as both the pre-wetting water for the lightweight aggregate and the mixing water, and we substituted BS and FA as Cm. In addition, we evaluated the fluidity, compressive strength, tensile strength, drying shrinkage, and accelerated carbonation depth of lightweight ternary cementitious mortars (TCMs) containing artificial lightweight aggregate and recycled water.

\section{Materials and Methods}

\subsection{Materials}

The Cm used in this study was ASTM type-I OPC manufactured by the Asia Cement Co. (Seoul, Korea), and the BS was obtained from Daehan Slag Co., Ltd., Gwangyang-si, Korea. FA manufactured at the D thermal power plant in Korea was used.

Figure 1 shows the SEM images of the cement, FA, and BS used in this study. Unlike FA, which is composed of spherical particles, the cement and BS have irregularly shaped grains. Table 1 lists the chemical compositions of the $\mathrm{Cm}$ used in this study.

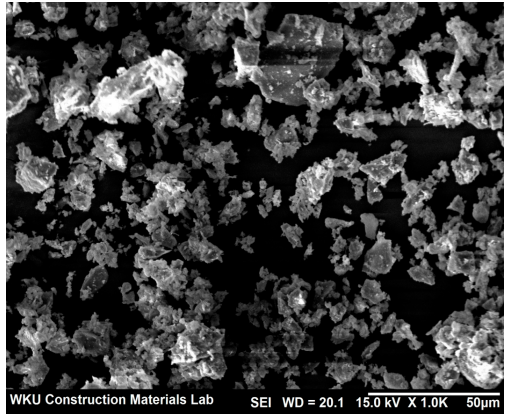

(a) Cement

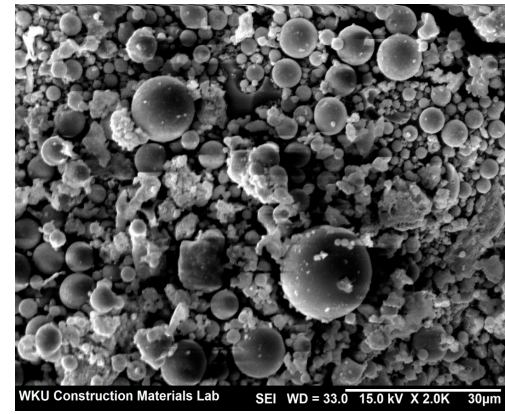

(b) Fly ash (FA)

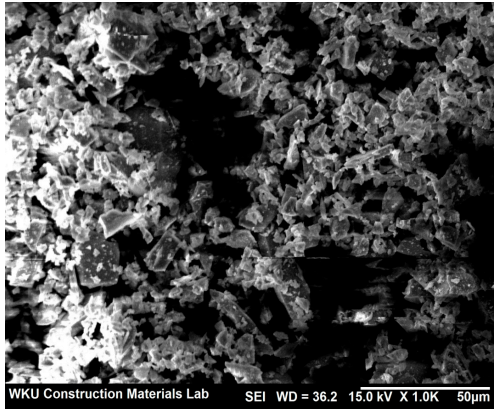

(c) Blast furnace slag powder (BS)

Figure 1. SEM images of cement (a), FA (b), and BS (c).

Table 1. Chemical composition of cementitious materials (cm).

\begin{tabular}{ccccccccc}
\hline Type & $\mathrm{SiO}_{2}$ & $\mathrm{Al}_{\mathbf{2}} \mathbf{O}_{\mathbf{3}}$ & $\mathrm{Fe}_{\mathbf{2}} \mathrm{O}_{\mathbf{3}}$ & $\mathrm{CaO}$ & $\mathbf{M g O}$ & $\mathbf{K}_{\mathbf{2}} \mathbf{O}$ & $\begin{array}{c}\text { Blaine } \\
\left(\mathbf{c m}^{2} / \mathbf{g}\right)\end{array}$ & $\begin{array}{c}\text { Density } \\
\left(\mathbf{g} / \mathbf{c m}^{3}\right)\end{array}$ \\
\hline Cement & 17.43 & 6.50 & 3.57 & 64.40 & 2.55 & 1.17 & 3430 & 3.15 \\
\hline $\begin{array}{c}\text { Blast furnace } \\
\text { slag powder (BS) }\end{array}$ & 30.61 & 13.98 & 0.32 & 40.71 & 6.43 & 0.60 & 4210 & 2.93 \\
\hline Fly ash (FA) & 64.88 & 20.56 & 6.06 & 2.58 & 0.80 & 1.45 & 3710 \\
\hline
\end{tabular}


As an artificial lightweight sand (LS), lightweight fine aggregate from KOEN, Korea, manufactured by calcining coal ash and dredged soil at $1100-1200{ }^{\circ} \mathrm{C}$, was used. The shape of the internal voids in the LS aggregate can affect the flowability and mechanical properties of the mortar sample. The optical micrograph of a single grain of the artificial LS in Figure $2 \mathrm{a}$ shows its shape, and the SEM image in Figure $2 b$ reveals the grain interior, which contains a large number of voids. Table 2 lists its physical properties.

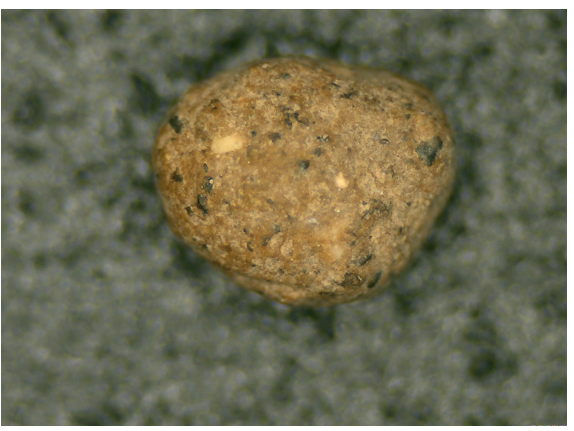

(a) Shape

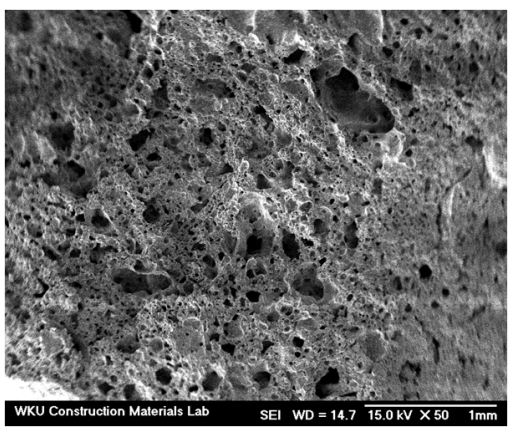

(b) SEM image

Figure 2. Optical (a) and SEM (b) images of the artificial lightweight aggregate.

Table 2. Physical properties of lightweight fine aggregate.

\begin{tabular}{ccccc}
\hline Type & $\begin{array}{c}\text { Fineness Modulus } \\
\text { (FM) }\end{array}$ & Density & $\begin{array}{c}\text { Water Absorption } \\
\text { Ratio (\%) }\end{array}$ & $\begin{array}{c}\text { Unit Weight } \\
\text { (kg/L) }\end{array}$ \\
\hline $\begin{array}{c}\text { Artificial lightweight } \\
\text { sand (LS) }\end{array}$ & 4.61 & 1.77 & 8.71 & 1010 \\
\hline
\end{tabular}

In the case of recycled water, by referring to a previous study [22], sludge was prepared with a 4:1 ratio of cement and sand-fines (less than $0.15 \mathrm{~mm}$ ), and recycled water with a sludge content of $5 \%$ was used as the pre-wetting and mixing water. Table 3 details the composition of the sludge used in this study.

Table 3. Composition of the sludge.

\begin{tabular}{ccccc}
\hline Mix. & $\begin{array}{c}\text { W/C } \\
(\mathbf{\%})\end{array}$ & $\begin{array}{c}\text { Water } \\
(\mathbf{g})\end{array}$ & $\begin{array}{c}\text { Cement } \\
(\mathbf{g})\end{array}$ & $\begin{array}{c}\text { Sand Fines } \\
(\mathbf{g})\end{array}$ \\
\hline Sludge & 50 & 200 & 400 & 100 \\
\hline
\end{tabular}

\subsection{Mix Proportions and Specimen Preparation}

Table 4 shows the mix proportions of the experimental cement mortar specimens.

Table 4. Mix proportions of the cement mortar specimens.

\begin{tabular}{|c|c|c|c|c|c|c|c|}
\hline Mix. & $\begin{array}{l}\text { BS } \\
(\%)\end{array}$ & $\begin{array}{l}\text { FA } \\
(\%)\end{array}$ & $\begin{array}{c}\text { Sludge } \\
\text { Content } \\
(\%)\end{array}$ & $\begin{array}{c}\text { LS } \\
(S * \%)\end{array}$ & $\begin{array}{c}\mathrm{W} / \mathrm{Cm} \\
(\%)\end{array}$ & $\begin{array}{c}W \\
\left(\mathrm{~kg} / \mathrm{m}^{3}\right)\end{array}$ & $\underset{\left(\mathrm{kg} / \mathrm{m}^{3}\right)}{\mathrm{Cm}}$ \\
\hline R5-C100 & 0 & 0 & & & & & \\
\hline R5-BS5FA5 & 5 & 5 & & & & & \\
\hline R5-BS10FA10 & 10 & 10 & 5 & 100 & 45 & 153 & 340 \\
\hline R5-BS15FA15 & 15 & 15 & & & & & \\
\hline R5-BS20FA20 & 20 & 20 & & & & & \\
\hline
\end{tabular}

The water-Cm ratio was fixed at $45 \%$, and the sludge content of the recycled water was $5 \%$, which showed good characteristics in a previous study [23]. The recycled water 
was used as both the pre-wetting water and mixing water. To make TCMs, 5-20\% BS and FA were used to replace part of the cement content.

Cubic specimens with dimensions of $50 \mathrm{~mm} \times 50 \mathrm{~mm} \times 50 \mathrm{~mm}$ were prepared via molding for compressive strength testing, and cylindrical specimens with dimensions of $\varnothing 50 \mathrm{~mm} \times 100 \mathrm{~mm}$ were prepared for split-tensile strength testing. In addition, $40 \mathrm{~mm} \times 40 \mathrm{~mm} \times 160 \mathrm{~mm}$ specimens were prepared for drying shrinkage and carbonation tests. We then demolded the specimens after $24 \mathrm{~h}$ and cured them in a water tank at $20^{\circ} \mathrm{C}$ until the required age $(7,28$, or 56 days). Mortar flow and compressive strength were measured according to KS L 5105 [24], and tensile strength was determined according to KS F 2423 [25]. Drying shrinkage was assessed using a contact gauge according to KS F 2424 [26]. For the carbonation test, the carbonation depth was measured using a phenolphthalein solution after a carbonation process in an accelerated carbonation chamber according to KS F 2584 [27].

\section{Results and Discussion}

\subsection{Mortar Flow}

Figure 3 presents the different flow values of the lightweight aggregate mortar samples with recycled water and ternary $\mathrm{Cm}$. The flow of the R5-C100 sample was the lowest at $\sim 176 \mathrm{~mm}$. The flow values of the TCM samples with BS and FA were all higher than that of R5-C100. Further, the flow of the mortar sample gradually increased with the amount of FA and BS. This increased flow was attributed to the spherical shape of FA, as shown in Figure 1, which likely caused a ball bearing effect, rather than BS, which was irregularly shaped.

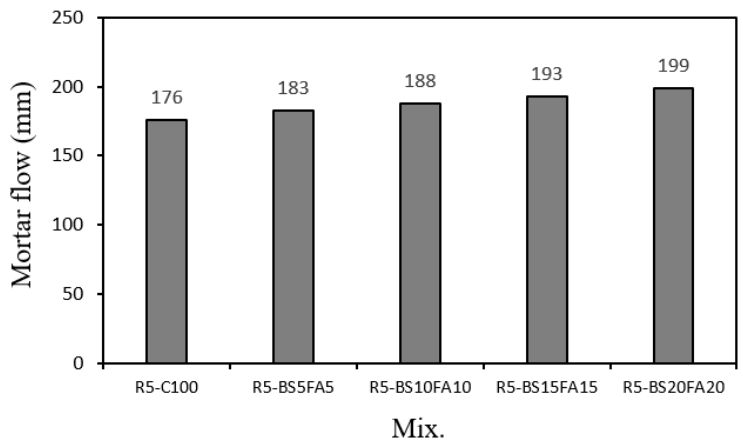

Figure 3. Mortar flow.

The flow of the R5-BS20FA20 sample, which had the highest amounts of BS and FA, was $199 \mathrm{~mm}$, which was $13.3 \%$ higher than that of R5-C100. Furthermore, each time the amount of BS and FA was increased by $5 \%$, the flow value of the lightweight TCM sample with recycled water increased by $\sim 2.6-4.2 \%$. It has been reported that the use of recycled water does not have a significant effect on the mortar flow [4]; similarly, this study found that the mortar flow was more affected by the use of $\mathrm{Cm}$ than the use of recycled water.

\subsection{Compressive Strength}

Figure 4 shows changes in the compressive strength of the lightweight mortar specimens with recycled water and ternary $\mathrm{Cm}$. After 7 days, the compressive strength of R5-C100 was $\sim 44.6 \mathrm{MPa}$, showing the highest value. The 7-day compressive strengths of the TCM specimens with BS and FA were $32.1-41.0 \mathrm{MPa}$, all of which were lower than that of R5-C100. Moreover, as the amount of BS and FA increased, the 7-day compressive strength of the TCM specimen tended to decrease. 


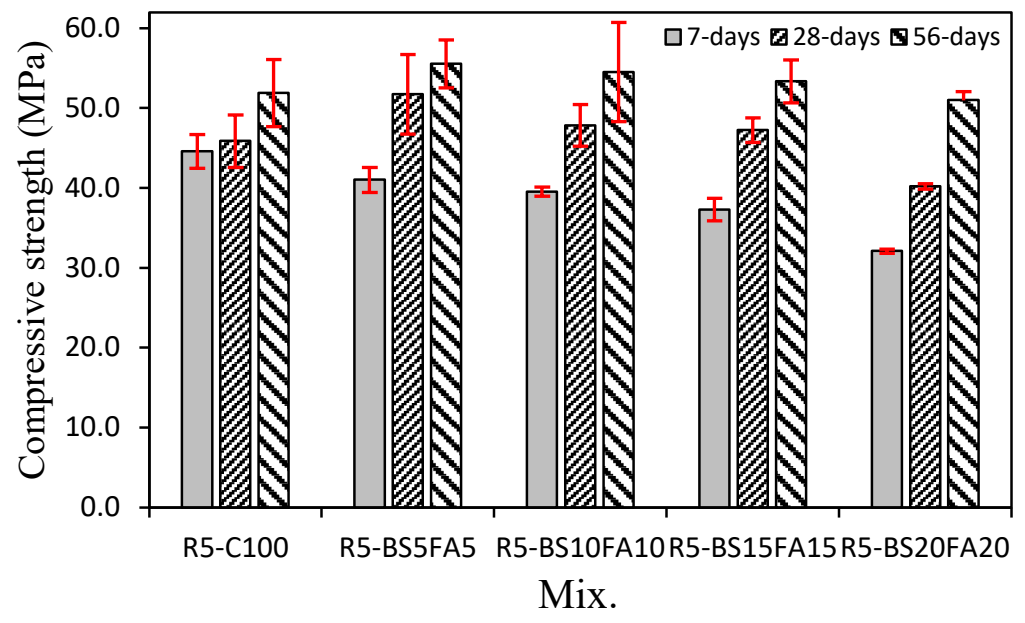

Figure 4. Compressive strength.

However, the evolution of the 28-day compressive strength showed a different trend. Specifically, the 28-day compressive strength of the R5-C100 control specimen was $\sim 45.9 \mathrm{MPa}$, whereas the 28-day compressive strengths of the lightweight TCM specimens containing BS and FA were $47.2-51.7 \mathrm{MPa}$; only the R5-BS20FA20 specimen showed a lower compressive strength (40.2 MPa) than R5-C100. In particular, R5-BS5FA5 showed the highest 28-day compressive strength of $\sim 51.7 \mathrm{MPa}$, which was $\sim 12.8 \%$ higher than that of R5-C100.

Interestingly, the R5-BS15FA15 specimen also showed a higher 28-day compressive strength of $\sim 47.3 \mathrm{MPa}$, although its total $\mathrm{Cm}$ amount was $30 \%$. This significant enhancement in performance might have been due to the filling action of fines in the recycled water [8] and the activation of the $\mathrm{Cm}$ reaction owing to the high alkalinity of the recycled water [28-30]. Therefore, these results suggest that the appropriate use of recycled water and $\mathrm{Cm}$ in a lightweight aggregate cement composite can effectively improve its compressive strength.

After 28 days, the strength continued to evolve, and the 56-day compressive strength of the R5-C100 specimen was $~ 51.9 \mathrm{MPa}$. In contrast, the compressive strength of R5-BS5FA5 (55.5 MPa) was the highest among the TCM specimens. Indeed, the 56-day compressive strengths of most TCM specimens with $\mathrm{Cm}$ were higher than that of R5-C100 without $\mathrm{Cm}$; only the 56-day compressive strength of the R5-BS20FA20 specimen (51.0 MPa) was similar to that of the R5-C100 specimen.

\subsection{Tensile Strength}

Figure 5 compares the 28-day tensile strengths of the lightweight TCM specimens with recycled water and ternary $\mathrm{Cm}$ with that of the control. The R5-C100 specimen without $\mathrm{Cm}$ showed the lowest tensile strength of $\sim 2.47 \mathrm{MPa}$, whereas those of the lightweight TCM specimens with BS and FA were $2.81-3.20 \mathrm{MPa}$, which were $13.7-29.5 \%$ higher than that of R5-C100. In particular, the tensile strength of the R5-BS5FA5 specimen, which had the highest 28-day compressive strength, was $~ 3.20 \mathrm{MPa}$, the highest among the mixtures and $\sim 29.5 \%$ higher than that of R5-C100. This increase compared to that of the control is more than double compared to that in the compressive strength (12.8\%). Therefore, the proper use of recycled water and $\mathrm{Cm}$ in the lightweight aggregate cement composite effectively increases both the tensile and compressive strengths of the cement composites. In this study, the improvement in the tensile strength was greater. 


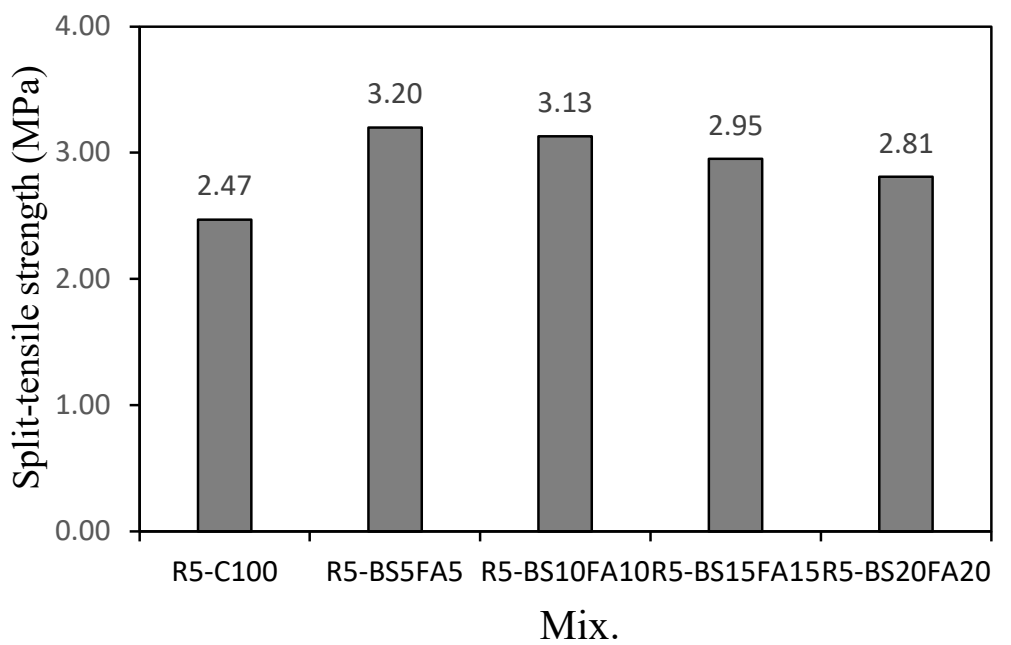

Figure 5. Tensile strength.

\subsection{Drying Shrinkage}

The drying shrinkage of lightweight mortar specimens with recycled water and ternary $\mathrm{Cm}$ is shown in Figure 6. After 56 days, the R5-C100 specimen without Cm showed the lowest drying shrinkage at $\sim 0.143 \%$ compared with the lightweight TCM specimens incorporating BS and FA. Specifically, the 56-day drying shrinkage of R5-BS15FA15 was $\sim 0.161 \%$, which was $\sim 12.5 \%$ greater than that of R5-C100, whereas that of R5-BS5FA5 $(0.154 \%)$ was relatively low among the TCM specimens. The higher drying shrinkage of the TCM specimens with Cm compared with that of the R5-C100 specimen without Cm was likely due to the increase in the mineral admixture content and the high fineness effect of the Cm particles used in this study [31,32].

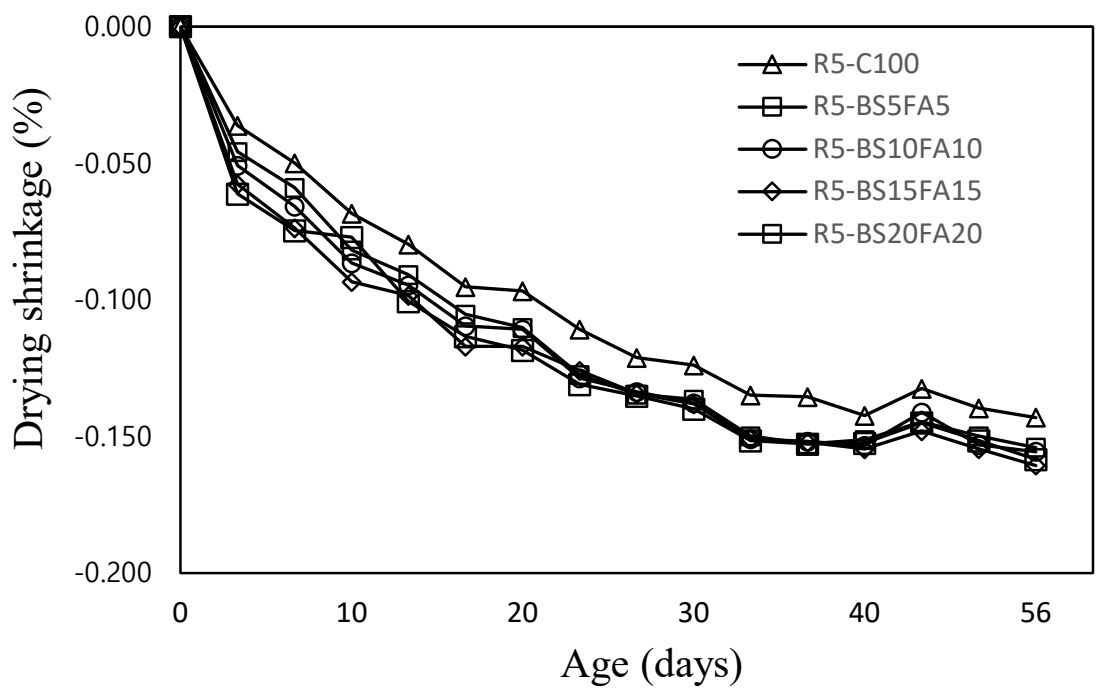

Figure 6. Drying shrinkage.

\subsection{Carbonation Depth}

Figure 7 shows the carbonation depths of the lightweight mortar specimens with recycled water and ternary $\mathrm{Cm}$ after 28 days of accelerated carbonation. The carbonation depth of the R5-C100 specimen without Cm was $\sim 1.56 \mathrm{~mm}$, whereas those of the lightweight TCM specimens with Cm were $\sim 0.84$ to $1.52 \mathrm{~mm}$, all of which were smaller than that of R5C100. However, as the amount of BS and FA increased, the carbonation depths of the TCM specimens gradually increased. In particular, the carbonation depth of R5-BS5FA5 was only $\sim 0.84 \mathrm{~mm}$, which was $\sim 46.1 \%$ smaller than that of R5-C100. The reason for this decreased carbonation depth was that the 56-day compressive strength of the R5-BS5FA5 specimen 
was the largest, and a denser cement matrix is considered to improve its penetration resistance to $\mathrm{CO}_{2}$ gas. Thus, this study found that the proper use of recycled water and $\mathrm{Cm}$ improved the compressive strength of the mortar by making its internal structure denser, which seems to have influenced the observed improvement in the carbonation resistance. Therefore, in this study, the R5-BS5FA5 showed the optimal performance in terms of its combination of compressive strength, tensile strength, and carbonation resistance.

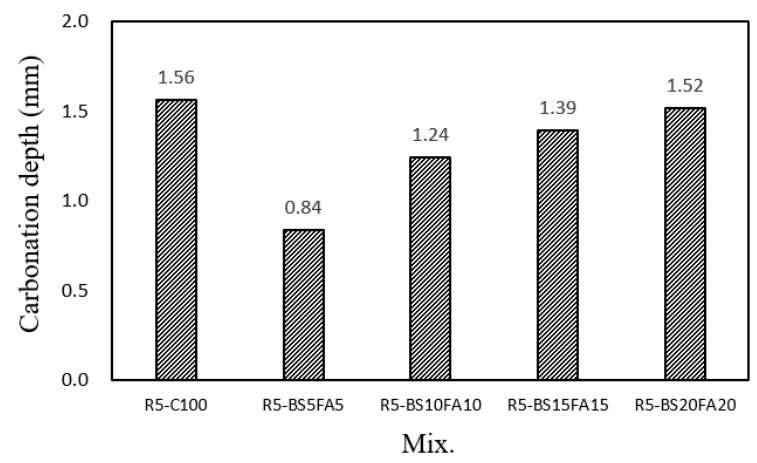

Figure 7. Carbonation depth.

\section{Conclusions}

(1) In this study, when the amounts of BS and FA were increased by 5\%, the flow value of the lightweight TCM specimen with recycled water increased by $\sim 2.6-4.2 \%$.

(2) The 28-day compressive strengths of the lightweight TCM specimens containing BS and FA were $47.2-51.7 \mathrm{MPa}$, except for that of R5-BS20FA20 (40.2 MPa), which was higher than that of R5-C100. In particular, the 28-day compressive strength of the R5-BS5FA5 specimen with 5\% BS and FA was $51.7 \mathrm{MPa}$, which was $12.8 \%$ higher than that of R5-C100.

(3) The 28-day tensile strengths of the lightweight TCM specimens incorporating BS and FA were $\sim 2.81-3.20 \mathrm{MPa}$, which were $\sim 13.7-29.5 \%$ higher than that of the R5C100 specimen. Therefore, the proper use of recycled water and $\mathrm{Cm}$ in lightweight aggregate cement composites is efficacious in improving the tensile and compressive strengths of the cement composite specimen.

(4) The drying shrinkage of the lightweight TCM specimens with BS and FA was relatively higher than that of the R5-C100 specimen.

(5) The carbonation depth of the R5-BS5FA5 specimen with 5\% BS and FA was $0.84 \mathrm{~mm}$, which was $\sim 46.1 \%$ smaller than that of R5-C100. The carbonation depths of all the lightweight TCM specimens containing $\mathrm{Cm}$ were $\sim 0.84-1.52 \mathrm{~mm}$ and were smaller than that of the R5-C100 specimen $(1.56 \mathrm{~mm})$.

In this study, the R5-BS5FA5 specimen incorporated with 5\% each of BS and FA showed the best performance in terms of compressive strength, tensile strength, and carbonation resistance.

Author Contributions: Conceptualization, S.-J.C.; Investigation, S.-J.C. and S.-H.B.; Data Curation, J.-I.L. and J.-H.K.; Writing-Original Draft Preparation, S.-J.C. and J.-I.L.; Writing-Review and Editing, S.-J.C. All authors have read and agreed to the published version of the manuscript.

Funding: This paper was supported by Wonkwang University in 2021.

Institutional Review Board Statement: Not applicable.

Informed Consent Statement: Not applicable.

Data Availability Statement: Not applicable.

Acknowledgments: The authors gratefully acknowledge Wonkwang University for the financial support of this work. 
Conflicts of Interest: The authors declare no conflict of interest.

\section{References}

1. Goo, H.C.; Hyun, L.S.; Hwan, L.M.; Wan, W.J. Influence of stabilizing agent for recycling water on engineering properties of cement mortar. J. Korea Inst. Build. Constr. 2005, 21, 81-88.

2. Xuan, D.; Zhan, B.; Poon, C.S.; Zheng, W. Innovative reuse of concrete slurry waste from ready-mixed concrete plants in construction products. J. Hazard. Mater. 2016, 312, 65-72. [CrossRef]

3. Chatveera, B.; Lertwattanaruk, P. Reuse of ready-mixed concrete plant sludge water in concrete containing an additive or admixture. J. Environ. Manag. 2009, 90, 1901-1908. [CrossRef]

4. Choi, S.-J.; Bae, S.H.; Lee, J.-I.; Kim, J.H. Strength and Durability Characteristics of Cement Composites with Recycled Water and Blast Furnace Slag Aggregate. Materials 2021, 14, 2156. [CrossRef]

5. Zervaki, M.; Leptokaridis, C.; Tsimas, S. Reuse of by-products from ready-mixed concrete plants for the production of cement mortars. J. Sustain. Dev. Energy Water Environ. Syst. 2013, 1, 152-162. [CrossRef]

6. Xuan, D.; Poon, C.S.; Zheng, W. Management and sustainable utilization of processing wastes from ready-mixed concrete plants in construction: A Review. Resour. Conserv. Recycl. 2018, 136, 238-247. [CrossRef]

7. Kim, Y.-Y.; Lee, H.-S. Utilization of ready-mixed concrete recycling water mixed with hot-rolled slag containing c12a7 and application characteristics of cement mortar. J. Rec. Const. Resour. 2021, 9, 92-99.

8. Sandrolini, F.; Franzoni, E. Waste wash water recycling in ready-mixed concrete plants. Cem. Concr. Res. 2001, 31, 485-489. [CrossRef]

9. Ghrair, A.M.; Heath, A.; Paine, K.; Al Kronz, M.A. Waste wash-water recycling in ready mix concrete plants. Environments 2020, 7, 108. [CrossRef]

10. Talaei, A.; Pier, D.; Iyer, A.V.; Ahiduzzaman, M.; Kumar, A. Assessment of long-term energy efficiency improvement and greenhouse gas emissions mitigation options for the cement industry. Energy 2019, 170, 1051-1066. [CrossRef]

11. Shubbar, A.A.; Jafer, H.; Dulaimi, A.; Hashim, K.; Atherton, W.; Sadique, M. The development of a low carbon binder produced from the ternary blending of cement, ground granulated blast furnace slag and high calcium fly ash: An experimental and statistical approach. Constr. Build. Mater. 2018, 187, 1051-1060. [CrossRef]

12. Kulekci, G. The effect of pozzolans and mineral wastes on alkali-silica reaction in recycled aggregated mortar. Period. Polytech. Civ. Eng. 2021, 65, 741-750.

13. Shen, D.; Jiao, Y.; Gao, Y.; Zhu, S.; Jiang, G. Influence of ground granulated blast furnace slag on cracking potential of high performance concrete at early age. Constr. Build. Mater. 2020, 241, 117839. [CrossRef]

14. Shubbar, A.A.; Al-Shaer, A.; AlKizwini, R.S.; Hashim, K.; Al Hawesah, H.; Sadique, M. Investigating the influence of cement replacement by high volume of GGBS and PFA on the mechanical performance of cement mortar. In IOP Conference Series: Materials Science and Engineering; IOP Publishing: Bristol, UK, 2019; Volume 584, p. 012022.

15. De Weerdt, K.; Kjellsen, K.O.; Sellevold, E.; Justnes, H. Synergy between fly ash and limestone powder in ternary cements. Cem. Concr. Compos. 2011, 33, 30-38. [CrossRef]

16. Chu, S.H.; Kwan, A.K.H. Co-Addition of metakaolin and silica fume in mortar: Effects and advantages. Constr. Build. Mater. 2019, 197, 716-724. [CrossRef]

17. Lemonis, N.; Tsakiridis, P.E.; Katsiotis, N.S.; Antiohos, S.; Papageorgiou, D.; Katsiotis, M.S.; Beazi-Katsioti, M. Hydration study of ternary blended cements containing ferronickel slag and natural pozzolan. Constr. Build. Mater. 2015, 81, 130-139. [CrossRef]

18. da Silva Andrade, D.; da Silva Rêgo, J.H.; Cesar Morais, P.; Frías Rojas, M. Chemical and mechanical characterization of ternary cement pastes containing metakaolin and nanosilica. Constr. Build. Mater. 2018, 159, 18-26. [CrossRef]

19. Cho, W.-J.; Park, E.-S.; Jung, H.-S.; Ann, K.-Y. Durability characteristics of ternary cement matrix using ferronickel slag according to the alkali-activators. J. Rec. Const. Resour. 2020, 8, 190-197.

20. Pliatsikas, I.; Robou, E.; Samouhos, M.; Katsiotis, N.S.; Tsakiridis, P.E. Valorization of demolition ceramic wastes and lignite bottom ash for the production of ternary blended cements. Constr. Build. Mater. 2019, 229, 116876. [CrossRef]

21. Lauch, K.-S.; Dieryck, V. Durability of concrete made with ternary cements containing slag or fly ash and limestone filler. In Proceedings of the International RILEM Conference on Materials, Systems and Structures in Civil Engineering, Lyngby, Denmark, 22-24 August 2016; pp. 178-189.

22. Jin, G.H.; Kim, K.-J.; Lee, M.-H.; Hyun Lee, S.; Cheon-Goo, H. Properties of cement mortar with solid content and leaving time of recycling water using stabilizing agent. JAIK 2003, 23, 355-358.

23. Oh, T.-G.; Kim, J.H.; Bae, S.H.; Se-Jin, C. A Study on the strength, drying shrinkage and carbonation properties of lightweight aggregate mortar with recycling water. J. Korea Inst. Build. Constr. 2020, 20, 391-397.

24. Korean Standards \& Certification Information Center. KS L 5105, Testing Method for Compressive Strength of Hydraulic Cement Mortars; Korean Standards \& Certification Information Center: Seoul, Korea, 2007.

25. Korean Standards \& Certification Information Center. KS F 2423, Standard Test Method for Tensile Splitting Strength of Concrete; Korean Standards \& Certification Information Center: Seoul, Korea, 2016.

26. Korean Standards \& Certification Information Center. KS F 2424, Standard Test Method for Length Change of Mortar and Concrete; Korean Standards \& Certification Information Center: Seoul, Korea, 2015. 
27. Korean Standards \& Certification Information Center. KS F 2584, Standard Test Method for Accelerated Carbonation of Concrete; Korean Standards \& Certification Information Center: Seoul, Korea, 2015.

28. Su, N.; Miao, B.; Liu, F. Effect of wash water and underground water on properties of concrete. Cem. Concr. Res. 2002, 32, 777-782. [CrossRef]

29. Vaiciukyniene, D.; Pundiene, I.; Kantautas, A.; Augonis, A.; Janavicius, E.; Vaiciukynas, V.; Alobeid, J. Synergistic Effect of dry sludge from waste wash water of concrete plants and zeolitic by-product on the properties of ternary blended ordinary Portland cements. J. Clean. Prod. 2020, 244, 118493. [CrossRef]

30. De Matos, P.R.; Prudêncio, L.R., Jr.; Pilar, R.; Gleize, P.J.P.; Pelisser, F. Use of recycled water from mixer truck wash in concrete: Effect on the hydration, fresh and hardened properties. Constr. Build. Mater. 2020, 230, 116981. [CrossRef]

31. Zhang, W.; Hama, Y.; Na, S.H. Drying shrinkage and microstructure characteristics of mortar incorporating ground granulated blast furnace slag and shrinkage reducing admixture. Constr. Build. Mater. 2015, 93, 267-277. [CrossRef]

32. Shruthi, V.A.; Tangadagi, R.B.; Shwetha, K.G.; Nagendra, R.; Ranganath, C.; Ganesh, B.; Kumar, C.L.M. Strength and Drying Shrinkage of High Strength Self-Consolidating Concrete. In Recent Trends in Civil Engineering. Lecture Notes in Civil Engineering; Pathak, K.K., Bandara, J.M.S.J., Agrawal, R., Eds.; Springer: Berlin, Germany, 2021; Volume 77, pp. $615-624$. 